\title{
La teoría del iceberg y la práctica de la alusión en los cuentos de Ernest Hemingway y de Francisco Coloane
}

The Theory of the lceberg and the Practice of Allusion in the Stories of Ernest Hemingway and Francisco Coloane

Tatiana Calderón-Le Joliff

Université Paris 13-N ord y Pontificia Universidad Católica de Santiago, Chile

E-mail: taticalderon@hotmail.com

- L PROPOSITO de nuestro estudio es delimitar varias nociones al interior

— de un género específico con la intención de percibir más nítidamente las características esenciales de la escritura de Ernest H emingway y de Francisco Coloane y compararlas. En esa perspectiva, el énfasis será puesto en dos elementos dentro de los cuatro estudiados: la alusión como herramienta estructural, la teoría del iceberg, el género del cuento y el fenómeno del vagabundeo. La alusión y la teoría del iceberg mantienen una relación formal y simbólica. La disposición formal de la escritura "tempanesca" permite la concretización de la alusión, la convoca. Del punto de vista simbólico, el témpano ofrece el aparente silencio del lenguaje. Su indeterminación hace surgir el sentido o los sentidos esenciales del texto gracias a la alusión. El cuento es el género que concentra todas las características necesarias al florecimiento de la alusión y de la teoría del iceberg. Por su brevedad y por la obligada concentración de la acción, constituyeel marco privilegiado de la alusión y dela escritura lapidaria. En fin, la temática del vagabundeo es esencial en la obra de los dos escritores. El vagabundeo se traspone a la escritura para transformar la alusión en un margen del lenguaje, y constituirse en su motivación principal. El estudio siguiente se concentra exclusivamente en desentrañar las relaciones entre alusión y teoría del iceberg y en determinar cuáles son los lazos conceptuales y significativos que unen el vagabundeo a la alusión. El anál isis breve de varios ejemplos apoyará nuestro discurso. 


\section{ALUSION Y TEORIA DEL ICEBERG}

\section{Una imagen singular}

El témpano es una imagen recurrente en la literatura del viaje, se podría decir quees un toposque enmarca la aventura, el viaje, particularmente en Julio Verne. H enri M ichaux (1899-1984), autor francés de origen belga, escribió un poema usando la imagen del iceberg. Ese poema constituye el fin de un viaje espacial y de una búsqueda poética. La relación entre las palabras del discurso literario y los témpanos reside en el hecho que los témpanos, al igual que las palabras, están en el centro de su imperio, el mar, sin mirar a nadie, como estatuas de dioses desconsiderando los hombres. Las enseñanzas de esta imagen muestran un deseo de un espacio elemental, marcado por la dureza mineral, por la estabilidad y, al mismo tiempo, de un lenguaje, careciendo de contingencia, del contacto humano y dotado de un valor intrínseco, autosuficiente. El témpano es una figura hiperbólica de la densidad, cerrada, intocable que rehúsa toda incertidumbre. En los dos autores, la alusión desactiva este cierre de la imagen hiperbólica del témpano.

\section{Imagen del témpano y escritura}

Las escrituras de Francisco Coloane y de Ernest $\mathrm{H}$ emingway se caracterizan por su uso de un lenguaje sencillo, conciso y elíptico. La brevedad de tal lenguajeno quita el denso poder sugestivo del discurso de los dos autores. El principio del iceberg se erige en torno a estas características. H emingway definió su estilo con la teoría del iceberg tal como lo expresó en $D$ eath in the Afternoon y en una entrevista con G eorges Plimpton: "I always try to write on the principle of the iceberg. There is seveneights of it under water for every part that shows. Anything you know you can eliminate and it only strengthens your iceberg. It is a part that doesn't show" (Giger, 1977: 11)². Coloane, sin analizarlo por su cuenta, consta de la misma particularidad. Jorge Edwards en un homenaje al escritor dice lo siguiente:

${ }^{1}$ I dea ya expresada en D eath in the Afternoon: "Siempre trato de escribir teniendo en cuenta el principio del iceberg. Los siete octavos desu superficie están debajo del agua por cada pedazo que muestra. Todo lo que uno sabe que puede eliminar solamente refuerza el iceberg. Es la parte que no muestra nada" (mi traducción). 
En muchos de los textos he tenido una impresión precisa, que antes no había tenido con tanta claridad: un buen cuento de Coloane es un artefacto, un hecho verbal, comparable a un témpano. Es un témpano de la imaginación. ¿Por qué? Porque la parte visible, equivalente al texto, a las pal abras que tenemos delante de los ojos, es la parte menor, un porcentaje pequeño de toda la historia (Edwards, 2002: E18).

"T émpano sumergido" deFrancisco Coloaney "H ills LikeW hiteElephants" de Ernest $\mathrm{H}$ emingway son dos cuentos que ilustran la disimulación y la densidad del témpano.

El primer cuento pone en escena un joven aventurero estancado, después de haber aceptado un trabajo, en una isla del extremo sur de C hile en una familia ensimismada en el silencio. En cuanto decide irse, espantado por el morboso mutismo de la casa, el dueño del hogar, $\mathrm{H}$ aberton, revela otro rasgo de su individualidad. Se descompone súbitamente el muro de silencio de $\mathrm{H}$ aberton y surgen palabras dictadas por el miedo. Sorprendido por esa verbosidad súbita, el joven se conmueve pero termina acobardándose.

¡Ś - me dije mirándolo, no sé bien si con desprecio o con rabia-, lo mismo que los otros; pero ninguno como yo vio lo que el témpano ocultaba debajo de las aguas! ¡N adie vislumbró la ternura de esa natural eza sumergida! ¡U n día tal vez he de volver a Puerto Róbalo! ¡Seré rico; el silencio del antiguo dueño lo transformaré en bullicio alegre; entonces me gustará hasta la joven viuda; con los niños, ya mozos, aparejaremos un cúter esbel to como un al batros y nosiremos por las islas arponeando lobos a la manera yagana!

Pero no he vuelto todavía (C oloane, 1999: 429-430).

La puntuación hiperbólica revela el malestar del joven y también del viejo $\mathrm{H}$ aberton. En el extracto, el joven se miente a sí mismo, piensa que va a poder actuar de manera diferente pero no puede quedarse en un lugar orientado hacia la muerte. En ese cuento aparece la famosa imagen del témpano quenos interesa. Se aplica al muro emocional que erige $\mathrm{H}$ aberton entre él y todo su entorno. La alusión al témpano se refiere a la soledad intrínseca del hombre y al irreme diable fracaso del lenguaje. El joven entrevé la ternura, pero presiente la inadecuación de los códigos de convivencia entre él y la familia de $\mathrm{H}$ aberton. H uye de la violencia que representa la ruptura del silencio.

En el cuento de $\mathrm{H}$ emingway, una pareja está sentada en el bar de una estación detren. Algunos indicios (la mención del río Ebro, el idioma de la mesera) permiten pensar que se encuentran en España de vacaciones. La intriga se resume fundamentalmente a un diálogo entre las dos personas acerca de una operación de índole desconocido. El cuento es muy corto. Las palabras usadas para dialogar esconden el fondo del problema y no hacen másque resaltar un aspecto 
superficial del lenguaje. La interioridad de los personajes está disimulada debajo de un lenguaje insípido e indiferente, frío. $\mathrm{H}$ emingway no deja que la bomba explote, hace surgir la tensión desde la aparente calma. El lector deduce que la no-mencionada operación es un aborto porque concierne esencialmente a la mujer y es un acto que devolvería al hombre su tranquilidad. La deducción se efectúa a partir de la alusiva imagen propuesta por la mujer.

"T hey look like white elephants", she said.

"I've never seen one", the man drank his beer.

"No you wouldn't have" (H emingway, 1987: 211)2

La mujer se refiere al paisaje, a las colinas y también a ella misma pero la imagen es contradictoria. El elefante, en la simbólica cristiana, es el emblema de la castidad, de la constancia y de la inocencia. Pero simboliza también el bautizo. En las líneas redondeadas de las colinas se atisba el cuerpo de la mujer embarazada. Así la aparente banalidad de la observación despliega, en algún modo, el imaginario poético de la mujer y refleja su aspiración y frustración. La imagen concentra al igual que el témpano una gran parte de la verdad que el hombre no al canza a descifrar. El autor usa los mecanismos arquetípicos del hombrey dela mujer para hacernos descubrir la infelicidad profunda y el miedo que las dos personas experimentan. El hombre está totalmente cerrado a la comprensión del mundo femenino. En tres frases, H emingway enfatiza el abismo entre la oferta poética y sugestiva de la mujer y la rudeza y materialidad del hombre. Este último asegura que la operación es un detalle, la mujer solamente quiere que todo vuel va a la armonía y que el hombre esté satisfecho. Pero la armonía ya está rota y desperdiciada en este no diálogo. La densidad del témpano proviene aquí de la importancia de la mirada. La teoría de $\mathrm{H}$ emingway se basa en la mirada del pintor. Q uiere que el lector imagine con la mirada, sienta con su corazón, y después vea lo esencial.

\section{Conclusión}

¿Por qué cotejar entonces lo que llamamos el principio del iceberg, lo que H emingway denominó the iceberg theory, con la escritura alusiva? La alusión yace al nivel simbólico debajo del lenguaje, como el témpano bajo el agua. Al nivel formal, se encuentra en los intersticios del texto, con sus omisiones, en el

2 "Parecen elefantes blancos", dijo ella, "N unca he visto a uno", el hombre tomó su cerveza, "N o, no lo hubieras visto" (mi traducción). 
silencio también. Así como la densidad del lenguaje de H emingway y Coloane se parece a la compacidad del témpano, la alusión representa la connotación que se puede deducir de esa perspectiva hierática.

\section{LA TEM ATICA DEL VAGABUN DEO}

\section{Contexto literario}

La función del vagabundeo, según M ichel M affesoli (1997), es abrirseal otro, al extranjero, es también una manera de acoger lo extraño y de integrarlo en la vida cotidiana. Remedio para el alma, el vagabundeo permite perderse en el afán de encontrarse denuevo. Como lo había visto Santo Agustino, peregrinatio es la expresión dela distanciaterminándose en una experiencia interior. Alexandre Laumonier, en el M agazine littéraire (1997: 18-43), revista francesa de literatura, habla del vagabundeo o el pensamiento del medio. Para él, el problema principal del vagabundeo es encontrar un lugar aceptable. El vagabundo, en la búsqueda de este lugar, se sitúa en un espacio muy particular: "el espacio intermediario", que sería el medio, en el sentido de un espacio situado entre dos universos, un espacio delimitado, líneas, margen o frontera, umbral, no man's land. Pero, más que una reflexión del afuera, es una reflexión sobre el medio que ocupan los escritores del vagabundeo: la distinción entre el sujeto y el mundo hace emerger un yo que es también una frontera, un yo que separa los dos espacios, interioridad y exterioridad - ni adentro ni afuera. Es el movimiento que conduce del no-lugar, del caos, al lugar, al cosmos, a una singularidad que emerge arriba de la convulsiva masa humana anónima. Es preciso abandonar el mundo para volver al original vacío en que nació el hombre. El vagabundeo sirve al hombre de luz reveladora, y le hace visible y pensable el mundo. En el mundo del vagabundeo sehace la experiencia de la fragilidad delo que ha sido propuesto 0 impuesto hasta ahora y de la precocidad inmadura de las concepciones del mundo, de las decisiones filosóficas y de las certezas. La alusión encarna al vagabundeo en el sentido que se erige también como una frontera, un lugar intermediario que permite el acceso del lector a una visión más esencial y abierta. Sirve de luz reveladora y permite recobrar un sentido universal.

\section{Temática fundamental de H emingway y Coloane}

El fenómeno del vagabundeo aparece reiteradamente en la obra de los autores. Los personajes de H emingway están siempreen la búsqueda de un sentido ocul- 
to. La Tierra del Fuego y la Patagonia son tierras de acogida para los marginales del mundo. Sin embargo, la perspectiva es diferente según H emingway o Coloane. $\mathrm{N}$ ick A dams es el personaje que enfatiza a través de su aprendizaje de la vida la esencia del vagabundeo. Pierde por capas su inocencia, de "Indian Camp" a "Big Two-H earted River" para finalmente encontrar algunas respuestas. En la obra de Coloane, cuentos como "La botella de caña" o "El Australiano" ilustran cómo la tierra es la que acoge y produce el vagabundeo y la marginalidad. El vagabundeo, como temática recurrente y significativa, está reivindicada por las alusiones en los cuentos. Se divide en dos movimientos: la huida y la búsqueda. La huida implica el movimiento (circular y vertical), el rechazo (modernidad, decadencia) y la marginalidad. La búsqueda puede separarse en dos planos: ontológico y literario. En el plano ontológico aparece una reflexión sobre el orden del mundo y la comunión con la naturaleza. Del punto de vista literario, la búsqueda engendra una reflexión sobre la escritura y el lenguaje. Esteúltimo punto se refleja esencialmente en H emingway. Estudiemos ahora, "Big TwoH earted River" de H emingway y "Tierra del Fuego" de Coloane.

$\mathrm{H}$ emingway es el especialista de la ambigüedad y del juego de pistas. La alusión reviste varias formas en su obra pero es preferentemente implícita. La alusión se percibe por el progresivo establecimiento de una codificación a veces desconocida del lector o de una ritualización. En el cuento de $\mathrm{H}$ emingway, el personaje principal, N ick Adams, se pasea en la naturaleza con el afán de pescar. A parentemente, nada parece sugerir un sentido oculto. Sin embargo, la imagen repetida del pantano como lugar peligroso y temible impulsa la determinación de otra realidad oculta bajo las aguas de la ciénaga. Nick Adams efectúa una huida disfrazada de paseo. La alusión se desenvuelve a través de la disimulación de una herida desconocida y difundida. El título, "Big Two-H earted River", representa la imagen de un corazón dividido aplicable al río pero también al propio corazón de $\mathrm{N}$ ick, fraccionado entre el miedo y la voluntad de ser feliz.

$\mathrm{N}$ ick did not want to go in there now. He felt a reaction against deep wading with the water deepening up under his armpits, to hook big trout in places impossible to land them. In the swamp the banks were bare, the big cedars come together overhead, the sun did not come through, except in patches; in the fast deep water, in the half light, thefishing would be tragic. In theswamp fishing was a tragic adventure. $\mathrm{N}$ ick did not want it. $\mathrm{H}$ e did not want to go down the stream any further today (H emingway, 1987: 180) ${ }^{3}$.

\footnotetext{
3 "M ás allá, el río entraba en el pantano. N ick no quería ir allá ahora. No le gustaba vadear con el agua escurriéndose bajo sus sobacos, para enganchar grandes truchas en lugares imposibles para pescarlas. En el pantano las orillas estaban desoladas, los grandes cedros opacaban la
} 
En el extracto se puede distinguir la aparente sencillez y casi pueril lenguaje usado por el narrador. El narrador es al mismo tiempo observador y conciencia de $\mathrm{N}$ ick, intuye todo lo que si ente. La natural eza es el exacto espejo simbólico delo que vivió $\mathrm{N}$ ick y de lo que quiere huir y purificar. C ada elemento se puede asimilar al estado de ánimo de $\mathrm{N}$ ick. La imagen del pantano trae la idea de su malestar profundo. Sus aguas negras y viscosas representan la parte sumergida del iceberg. El lector vislumbra un segundo plano. Pero no lo puede determinar al menos que lea la totalidad de las andanzas anteriores de N ick. Se puede deducir una alusión simbólica y autoalusiva reflejada en el margen del lenguaje. EI pantano alude a la guerra, más precisamente al fango de las tranqueras cavadas por los soldados dela Primera Guerra M undial. N ick mezcla así dos realidades, lo presente y lo pasado, el paraíso y el infierno, pero no logra completamente curar su herida. En el apellido de N ick mismo, Adams, se percibe la alusión al hombre original y su caída. El lector tiene entonces la difícil tarea de encontrar por sí mismo lo esencial. El escritor no le da nada, sólo pistas. La alusión está totalmente agazapada, nada deja presagiar estrictamentela doble lectura. El lector tiene que investigar y vagabundear al acecho de su sentido. Su descubrimiento convierte el paseo de $\mathrm{Nick}$ en un vagabundeo catártico. El vagabundeo se divide en dos movimientos aquí: el del personaje buscando una felicidad perdida y el del lector tratando de descifrar, gracias a la alusión, la razón de esta búsqueda.

"Tierra del Fuego" narra la huida de tres hombres pertenecientes a la armada de Julio Popper (buscador de oro), Shaeffer, Spiro y N ovack. Codiciando la riqueza que Popper recoge sin compartirla, deciden iniciar una sublevación rápidamente derrotada. Shaeffer, herido, presiente la venida de la muerte pero $\mathrm{N}$ ovack, conservando una solidaridad estricta heredada de su formación militar, se ocupa de é mientras Spiro aprovecha dehuir. Los dos hombres se instalan en una cueva y viven de lo que la naturaleza les proporciona. U na cierta armonía se desarrolla en el seno de la naturaleza, la fraternidad desplaya cual repliegue de una ola cuando Shaeffer descubre oro en la osamenta de una ballena. Varias alusiones aparecen en el cuento desde la más evidente, citacional, hasta la más eclipsada, autoalusiva. N os concentraremos en tres al usiones.

Así lo hizo y colgó a tres o cuatro individuos en los postes que marcaban los linderos de sus pertenencias, poniéndoles un letrero que decía: "Lasciate ogni speranza voi ch'entrate" la frase de Dante que advertía a los humanos que

luz, el sol no podía penetrar, o solo con rayos difusos; en la corrienterápida, en la semioscuridad, la pesca sería trágica. En el pantano, pescar era una aventura trágica. N ick no quería. N o quería más aventurarse en el arroyo por hoy día" (mi traducción). 
perdieran toda esperanza al traspasar los umbrales del infierno. $\mathrm{Ni}$ los onas ni los aventureros del arroyo Beta conocían La divina comedia; pero más elocuente que la lengua de $D$ ante fue para ellos el cráneo mondo de los esqueletos, sobreloscuales se paraban los caranchos ahítos defestín (Coloane, 1999: 313).

Coloane, con esta cita en el idioma original, alude al Canto tercero de La divina comedia deD ante. La inscripción apareceen la puerta del Infierno delante de la cual se encuentra $D$ ante antes de seguir con su viaje con Virgilio en el Acheron, el río de las al mas condenadas. La cita demuestra a la vez la erudición de Julio Popper, aclara su ascendencia sobre el resto de los aventureros y opone la acción a la literatura. La cita ilustra el acto violento ejercido por Popper y denuncia el placer que ha tomado. U na otra alusión aparece en la forma de una cita troncada: " $¡ H$ ay que aullar siempre con el lobo, nunca contra el lobo!... profirió Shaeffer, atizando unas pocas brasas que quedaban entre la ceniza apegada a la piedra" (C oloane, 1999: 323). La alusión al libro Léviathan (1651) del filósofo y pensador político inglés Thomas H obbes (1588-1679) es evidente. "In a state of nature, man is a wolf to men". H obbes considera que el estado de natural eza es un estado de guerra de uno contra uno. La entrada en la sociedad se convierte en necesidad. Los hombres, para preservar su vida y vivir en paz, renuncian al estado de guerra y eligen una autoridad superior: el soberano. Este hereda de todo lo propio de los individuos en el estado de naturaleza para convertirse en el detentor exclusivo. El Leviatán, este antropomorfismo utilizado por el filósofo, posee un poder absoluto e ilimitado a cambio de una paz civil llevada a los individuos. La imagen del lobo es atribuida a Popper aunque, según $\mathrm{H}$ obbes, en una transposición a la situación total mente anárquica que viven los buscadores de oro, Popper es el hombre que organizó un mundo y manipuló los hombres para su beneficio. Es entonces, por una parte, el Leviatán, detentor del poder pero está lejos de entregar una paz civil; por otra, es el lobo dominante que no perdona ni el error ni la debilidad. La alusión revela una situación de crisis prohibiendo el desarrollo de una sociedad normativa. Laanormalidad de la sociedad conformada por los buscadores de oro genera la marginalidad y el vagabundeo. La tercera alusión y la más difundida es la alusión al personaje histórico Julio Popper y a las masacres de los indios onas. Coloane retoma las características esenciales e informativas de este personaje real para darle una contextura, darle vida. Su caracterización es ambigua. Coloane, a través de los diferentes puntos de vista, Shaeffer, N ovack, el narrador, muestra sucesivamente un hombre monstruoso, hábil y erudito. A pesar de la denuncia, Popper fuerza a la admiración. Los indios onas están mencionados a través de las reminiscencias de Novack, que emite un sentimiento de culpabilidad por haber cortado las orejas de los indios por una libra esterlina. Coloane usa un 
hecho conocido para instalar y vislumbar el drama. La alusión a otros textos o eventos históricos resal ta las mismas características de irremediable soledad y acentúa la dificultad de adaptación de estos personajes errantes al mundo natural que los rodea y a una sociedad constituida. Están condenados a permanecer tránsfugos.

En los dos autores, la escritura está orientada hacia una asimilación del hombre a la natural eza y hacia la alienación, fenómeno percibido por la concisión y la aceleración sintácica. El recurso a la alusión refleja un sentimiento de crisis y permite la amplificación de las imágenes.

La alusión, en los cuentos de H emingway y de Coloane, funciona en torno a la teoría del iceberg. Es decir que su modal idad provienea la vez de la disimulación, de la ambigüedad y del silencio. El vagabundeo o la alusión como margen de la escritura demuestra que la alusión que necesita estar percibida por el lector le ofrece una multitud de significados que tiene que elegir. Al término de su vagabundeo intelectual encontrará su propio sentido esencial de la verdad. La obra de los dos autores consta de una temática común: una búsqueda del individuo por sumarse a la materia cósmica universal. Ligado a este fenómeno, o más bien dependiendo de esa voluntad, el vagabundeo aparece como el único medio para llegar a la cohesión universal. Supone la búsqueda, la observación de sí mismo, o la huida hacia un mundo mejor. Presume también, en la visión judeo-cristiana, la búsqueda del paraíso perdido. Los hombres de Coloane y H emingway, por la mayoría tránsfugos, inadecuados, necesitan encontrar la armonía original.

\section{BIBLIO GRAFIA}

Coloane, Francisco. 1999. Cuentos completos: Coloane. Santiago: Aguilar Chilena de Ediciones.

Edwards Jorge. 2002. "H omenaje: Francisco C oloane, Lostémpanos de Coloane”, en El M ercurio. Santiago, Chile. 1 de septiembre, E18.

Giger, Romeo. 1977. The creative void: H emingwaysiceberg theory. Bern: Francke. $\mathrm{H}$ emingway, Ernest. 1987. T heC ompleteShort Stories of Ernest H emingway. N ew York: The Finca Vigia Edition.

Laumonier, Alexandre. 1997. "L'errance ou la pensée du milieu” en M agazinelittéraire $\mathrm{N} 0353, \mathrm{pp} .18-43$.

M affesoli, M ichel. 1997. D u nomadisme, vagabon dages initiatiques. Paris: Le Livre de Poche, Biblio-Essais, L.G.F. 